BRIT. J. GRIMINOL. VOL. 34 SPECIAL ISSUE 1994

\title{
THE GROWTH OF IMPRISONMENT IN GALIFORNIA
}

\author{
Frankin E. Zimring and Gordon Hawkins*
}

This article reports on a study of trends in imprisonment in the state of California over the period 1980-91. Documenting and analysing imprisonment in California is important to an international audience for two reasons. First, the pattern in California since 1980 is representative of a widespread trend in the United States of expansion in the scale of the prison enterprise. At least 90 per cent of American states are currently imprisoning offenders at a higher rate than at any other time in the twentieth century. The unprecedented expansion in California prison population is part of this pattern; and studying events in Galifornia is one approach to comprehending developments and conditions in most American states.

The second reason why California's situation demands attention is that the growth in imprisonment in that state has been singular in both its pace and its magnitude. The number of prisoners in California increased more than fourfold in 11 years. The current 104,000 prisoners in California is by far the largest prison population in the Western world, more than twice the national prison populations of West Germany and Great Britain. Never has a prison system grown by so much in so short a time during a period of political and social stability. Figure 1 compares the 1990 prison population in California and three other large American states with national prison populations in major European countries.

At the beginning of the 1980s, each of the European systems profiled was larger than all of the state systems. By 1990, three of the American state systems had grown to surpass each of the three European systems; and Florida was larger than Germany and Italy. The average major state system doubled in the decade while the average European system declined modestly.

The second visually striking conclusion from Figure 1 is that California was in a category by itself in prison growth during the 1980s. The other three major American systems averaged growth levels about half that experienced in California. The fourfold increase in this major state to a prison population twice as large as any Western European country in 1990 seems a singular event in American correctional history.

Our presentation of data from the Galifornia study proceeds in two parts. The first part (The California Story) uses statistics from California and sister states to document: the pace and extent of prison population growth in California; the extent to which the California pattern reflects the experience of other American states; the correlation between variation in potentially explanatory variables like crime and arrest rates and changes in imprisonment rates; and the way in which recent California experience has been used for projecting further growth in the prison system.

The second part of the analysis (Policy Perspectives) will discuss three of our findings which are of importance to students of imprisonment policy in Western democracies. We seek to draw particular attention to the open-ended potential for prison population growth in periods of stable criminality; the enormous margin of error generated from

* Earl Warren Legal Institute, University of California at Berkeley. 


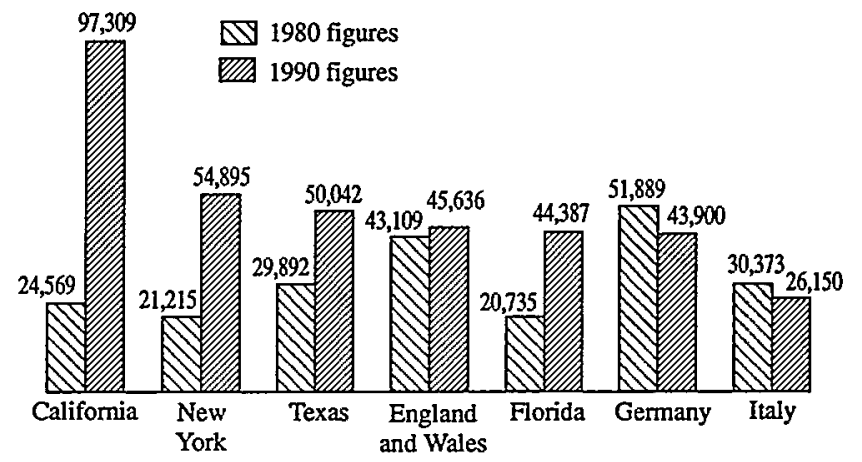

FIG. 11980 and 1990 Prison Populations in Major Systems (US Bureau of Justice Statistics, Prisoners in 1990 (United States); Home Office Statistical Service, Prison Statistics, England and Wales 1981, 1991 (England and Wales); Istituto Nazionale di Statistica, Annuario Statistico Italiano, 1981, 1991 (Italy); Statistiches Bundesamt, Statistiches Jahrbuch, 1991 (Germany))

estimates of future prison populations that are derived from straight-line projections that use high-growth periods as a base; and the opportunities presented by rapid and extensive growth in imprisonment in California to study the nature and extent of the incapacitation effect generated by changes in correctional policy.

\section{The California Story}

The pace and extent of Califormia growth

Figure 2 shows the variation in the number of prisoners and the rate of imprisonment in California from 1950 to 1990 .

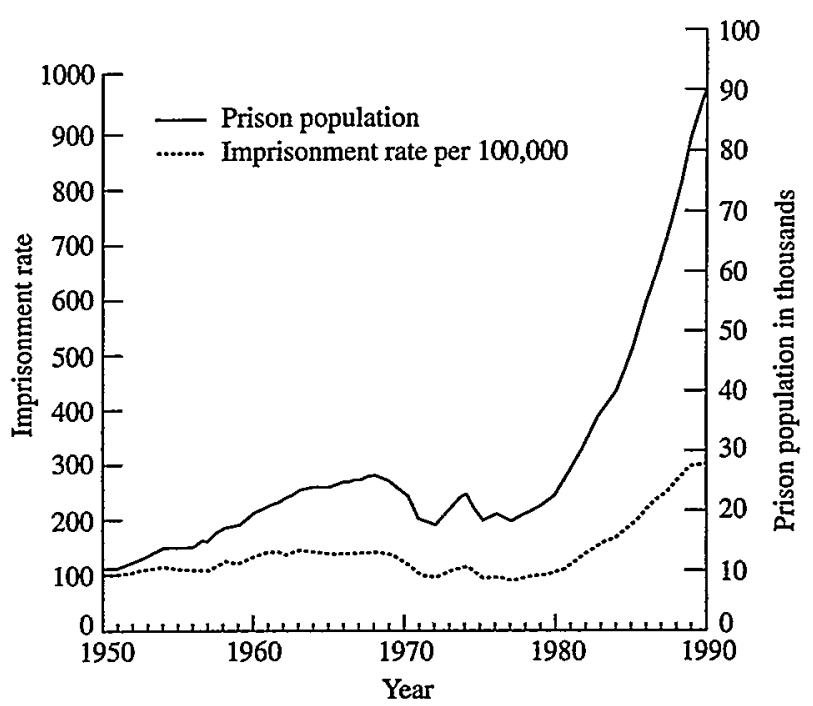

FIG. 2 Trends in Prison Population and Rate of Imprisonment per 100,000 in California, 1950-90 (Galifornia Department of Corrections, Prisoners and Parolees Series, 1988, 1989, and 1990) 
The number of prisoners climbed steadily under the pressure of expanding population from 1950 to 1968 , while the rate of imprisonment held steady. Both numbers of prisoners and rates of imprisonment per 100,000 population dropped in the early 1970s with the drop in the rate of imprisonment more than balancing increases in state population, so that prison numbers do not exceed their mid-1960s levels for 14 years.

In January 1980, while the number of prisoners was at an average level of 23,000 for the 1970 s, the rate of imprisonment reflected in that figure had fallen by more than 25 per cent since 1968. From 1981 onward, both numbers and rate increase without interruption. Even as the base rate of imprisonment increased throughout the 1980s, the rate of increase from that base does not diminish. By the end of 1985, the prison population had more than doubled from its 1980 population base. By the end of 1990 , the population had doubled once more.

Figure 3 shows the growth for both prison and jail population in California by year during the 1980s. The prison population consists of convicted felons sentenced to terms of more than one year in state custody (though less time may be served). The jail population consists of persons convicted of felonies and misdemeanours who are sentenced to less than one-year terms and those awaiting trial who are held in custody. Jails are under local county management in California.

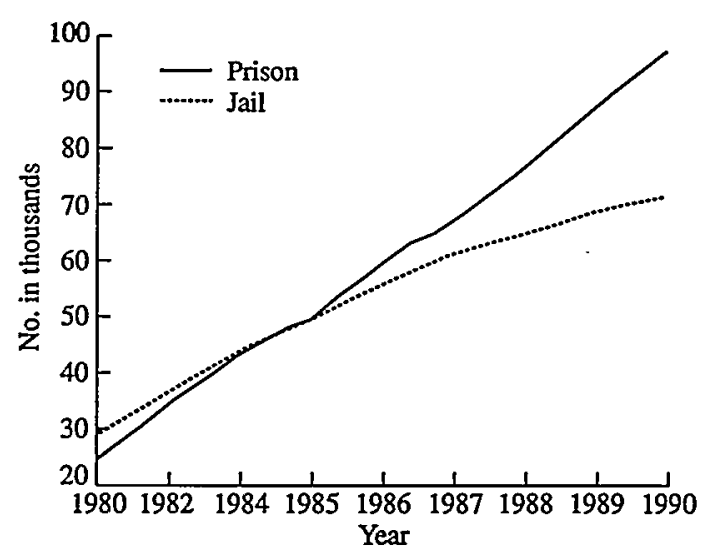

FIg. 3 Prison and Jail Populations by Year in California, 1980-90 (California Department of Corrections, California Board of Corrections)

Both jail and prison populations increased substantially through the decade, but the pattern for jails was slightly different. Jail population expanded from 28,946 to 70,845 over the $1980 \mathrm{~s}$, but three-quarters of that growth occurred prior to 1987 . The annual growth in jail population had slowed to about 5 per cent by the decade's end.

Prisons passed jails in total population in 1985 and continued to grow in the late 1980 s at a rate twice that of jails. After 1985, the California system added more prisoners each year than the system added in the average decade between 1950 and 1980 . Between 1980 and 1991, California experienced seven times as much total growth in prison population as in the previous three decades combined.

The figure most comparable to English and European prison statistics is the combination of prison and jail numbers. During the $1980 \mathrm{~s}$, the total number in prisons 
and jails more than tripled from 52,000 to 170,000 , while state population increased 30 per cent. In one decade, one American state added more than 100,000 extra prison and jail inmates to its correctional population.

\section{Parallels to the experience of other states in the United States}

The correctional growth experience in California in the 1980s was simultaneously a singular event in American correctional history and not untypical of the performance of most other states during this most unusual decade. What was distinctive about the California experience was the sheer size of the expansion: no state had ever added 75,000 prisoners or increased prison and jail populations by 115,000 in one decade. Yet the trend in California was not that far removed from the pattern in most other American states. Figure 4 compares changes in California's rate of imprisonment with parallel data for the rest of the United States in the aggregate.

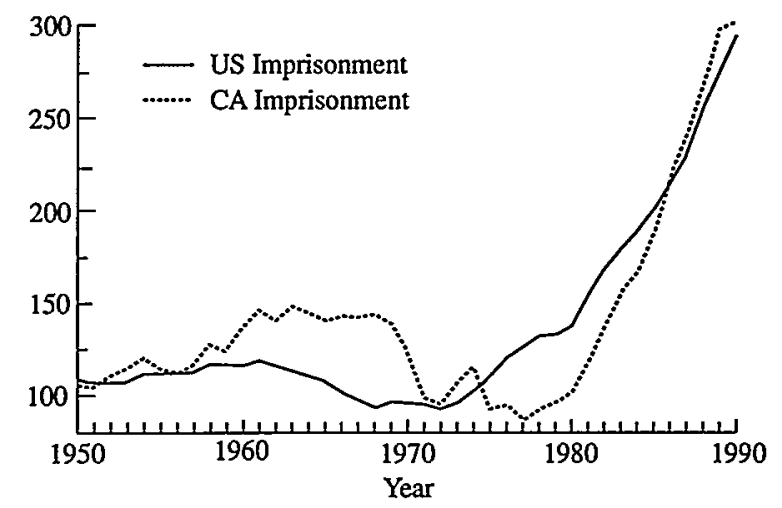

FIG. 4 Rates of Imprisonment per 100,000 of Population: California and the United States, 1950-90 (California Department of Corrections, Prisoners and Parolees Series)

The two trend lines are quite similar during the 1980s. Rates of imprisonment start to rise in the mid-1970s in the other states, so that by 1980 there was a significant gap between California and non-California rates of imprisonment. But during the 1980s, California imprisonment rates first closed the gap and then moved into a slight lead.

Three statistical elements combined to produce the unprecedented build-up in prisons. First, California followed the national trend toward higher rates of imprisonment and this feature alone would account for about half of California's prison population growth. The 1980s were a decade in which the average jurisdiction's prison population more than doubled. A second factor contributing to the explosive growth in prison population was the interaction of these higher imprisonment rates with a 30 per cent increase in the state's population.

The third development in California that helps to explain the expansion in prison 
population is that California also changed its standing in imprisonment levels relative to other states. In 1980 California's rate of imprisonment per 100,000 was in the middle of the state distribution, ranking twenty-fourth in relation to the 50 states and the District of Columbia (Zimring and Hawkins 1991b: 149). By 1991 California's rank had climbed to fifteenth (US Department of Justice 1992: 1).

Each element of this experience interacted with the other elements in a multiplicative way. A 30 per cent increase in state population would produce a 30 per cent increase in prison population if imprisonment rates were stable. But a 30 per cent increase in state population would be causally associated with an additional 90 per cent increase in prison population due to the higher population at risk if the imprisonment rate tripled at the same time that state population expanded. With this kind of interaction the extent of change that can be attributed to a particular contributing factor is debatable; the order in which changes are placed into the equation could influence the amount of leverage attributable to a particular change.

\section{Causes and non-causes}

What forces are associated with this unprecedented growth in imprisonment? The historical evidence we examined clearly excludes a number of explanations for the increase in imprisonment and suggests two trends that between them account for a major share of that increase.

Whatever may have caused the explosive growth in prison population, crime trends in California, and the level of arrests for non-drug felonies are not significantly related to the imprisonment boom. Crime rates decreased during the first half of the $1980 \mathrm{~s}$ in California and that pattern holds whether the subject is total reported crime, index felony offences, or violent offences. The decline in crime while prison population was soaring might tempt many observers to conclude that the increase in imprisonment was a major cause of the decline in crime. The plausibility of that hypothesis suffered a setback in the latter part of the decade as rates of serious crime edged back toward 1980 levels while the additional imprisonment imposed each year in California increased in the late 1980 s by unprecedented amounts. For the decade as a whole, there is no apparent relationship between trends in crime and trends in imprisonment, as is shown in Figure 5.

If the crime trends in California do not explain the changes in imprisonment, what about changes in criminal justice policy? Here the pattern is less clear. No major change in sentencing structure or legislatively announced punishments is associated with the expansion of prison population that began in 1980. The switch from indeterminate to determinate prison sentences in California was effective in 1977 and produced a substantial decline in prison numbers at first, because a large number of offenders with greater-than-average prison sentence lengths under the old regime were given sentence reductions under this new system (Zimring and Frase 1980: 864). These major structural changes did not for the most part constrain the discretion of the courts to select or avoid imprisonment as a sanction. There were some legislative changes that may have influenced the rate of imprisonment, such as a law disapproving lesser charges and non-prison sanctions that came into effect in the early $1980 \mathrm{~s}$. And the same spirit that inspired the sentencing reforms of the mid-1970s may have led to a general toughening in public attitudes toward offenders and in judicial sentencing policy. But 


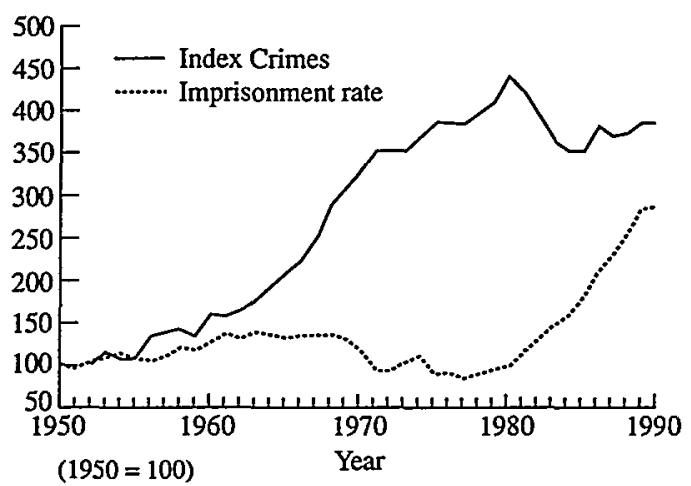

FIG. 5 Trends in Index Crimes and Imprisonment Rates in California, 1950-90 (FBI Uniform Crime Reports; California Department of Corrections, Prisoners and Parolees Series, 1988,1989 , and 1990)

no piece of legislation appears to have been directly responsible for most of the increase in imprisonment.

The two statistical trends most clearly responsible for the increase in imprisonment are increases throughout the decade in the proportion of felony convictions that produced sentences of imprisonment and the explosive growth in the number of individuals arrested for, convicted of, and imprisoned for drug offences. Figure 6 shows the proportion of felony convictions leading to prison commitment in California for each year from 1980 to 1990 .

Figure 6 shows the principal cause of the imprisonment boom in California and if anything understates the nature of the shift toward more severe sanctions as the explanation of that boom. The increases in rates of imprisonment during the $1980 \mathrm{~s}$ were much greater for crimes of lesser seriousness, such as larceny and automobile theft that have low rates of imprisonment at the beginning of the decade, than for more serious crimes, such as robbery, which have higher base rates of imprisonment. The number of robbers in California prisons increased by 104 per cent between 1980 and 1990, as compared with a 338 per cent increase in the total number of prisoners and a 565 per cent increase in the number of persons imprisoned for the less serious residual categories of theft.

The influences that led to this 'get tough' sentencing policy were more a matter of sentiment than legislation. Without any central direction, the large increases in the percentage of offenders imprisoned represent aggregate measures of the discretion of individual prosecutors and judges all over the state of California. This progressive toughening was not evenly spread over all California counties. Los Angeles county experienced a larger increase in the percentage of felons sent to prison than non-Los Angeles counties. Nevertheless, the extent of the general shift toward more severe discretionary decision making was not merely remarkable in California, but reflected a pattern throughout the United States.

Substantial increases in arrest, conviction, and imprisonment for drug offences are the other major influence on the general rate of imprisonment that our study identifies. Between 1980 and 1990 the annual total of males in prison for drug offences in California grew fifteenfold from approximately 1,500 to 22,600. Another way of stating 


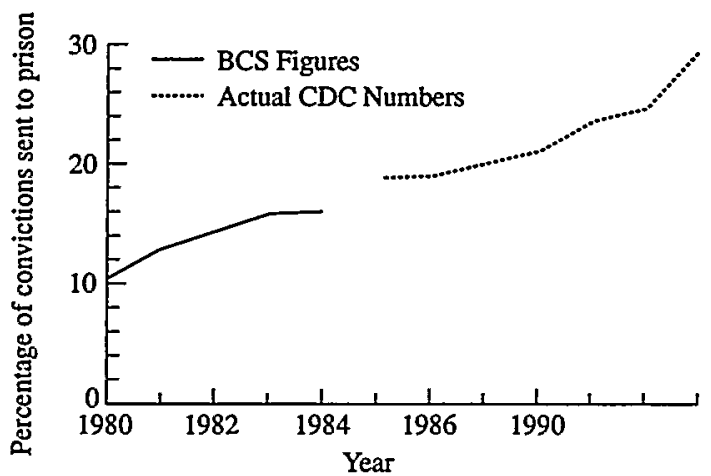

FIg. 6 Proportion of Non-drug Felony Convictions Resulting in Imprisonment in California, 1980-90 (California Department of Corrections (imprisonment numbers); Bureau of Criminal Statistics (conviction numbers))

the magnitude of the change is to point out that more persons were in prison in California for drug offences in 1991 than were in prison for all offences in California at the end of 1979 (Zimring and Hawkins 1992b: 32).

Is the large increase in drug cases evidence of a drug crime wave or merely of changing policy in relation to drug offences? Unlike non-drug felony crime, the number of felony arrests for drug offences increased rapidly throughout the $1980 \mathrm{~s}$, so that a comparison of arrest trends and imprisonment trends is not decisive on the question of causation in the same way that holds for burglary and robbery. There are, however, strong indications that changes in drug law enforcement rather than increases in drug taking have fuelled both arrest and imprisonment totals. National household surveys that have become the official governmental benchmark for illicit drug use indicate a persistent decline in the prevalence of the use of most illicit drugs during the 1980s (Zimring and Hawkins 1992a: 199). Yet imprisonment rates for drug crime rose sharply on a national basis after a high-intensity 'War on Drugs' was launched in the mid-1980s.

It is probably correct that the new policy emphasis on drugs was the principal reason for shifts in drug arrests as well as the increased severity in the sentencing of drug offenders. Yet an increase in drug arrests is far from a sufficient cause of the increase in prison population in California. From 1966 to 1976 the volume of drug arrests in the state of California increased almost twentyfold while the number of persons in prison fluctuated almost without trend (Zimring 1990: 23). What happened in the 1980s to produce the explosion in drug imprisonment was an interreaction between a shift toward 'get tough' attitudes and an increasing volume of drug arrests.

Identifying a movement in public and official sentiment as the major cause of California's imprisonment boom raises as many questions as it resolves. Criminal offenders never rate highly in public favour; but why the changes noted in the 1980s? Furthermore, once this sort of trend takes hold in a criminal justice system, what forces limit the influence of punitive sentiments? And how are new equilibrial conditions found and maintained? These are among the significant questions that careful studies of the California scene might profitably address. 


\section{Growth and the projection of future prison population}

Rapid growth in the population under confinement puts pressure on those who maintain the system to make projections of future needs and to formulate and implement plans to meet those needs. In California, as the expanding prison population consumed the space added in the 1990s, the capacity of the system to accurately project future population and construction needs became a central element of criminal justice planning.

In 1991 the California Department of Corrections issued an official projection that by mid-year 2000 , or nine years and three months after the projection, California prisons would confine 224,641 prisoners. The State Department of Finance estimated that $\$ 10.2$ billion in additional construction would be necessary over the next ten-year period to hold that number of prisoners under conditions of tolerable crowding (California State Department of Finance 1991: 24).

That level of prison population for a single American state would be unprecedented, but at the same time would represent continuity in trend. The 224,641 estimate projected a smaller proportional growth than California had experienced in the previous nine years (see Figure 1). Yet the total projected growth was phenomenal. 224,000 prisoners would represent a prison population ten times as large in the California of the year 2000 as had existed 20 years before. Indeed, the projected total would exceed the total number of prisoners in all federal and state facilities in the United States in 1973.

The method used to obtain these estimates was a 'straight-line' projection that gave special weight to trends in prison admission closest to the time the projection was made and continued those trends forward for however many years the policy analyst had requested. Because heavy emphasis was placed on short-term trends, relatively small fluctuations in prison admissions created large changes in the projected prison populations.

A dramatic example of this occurred in California between the autumn of 1990 and the autumn of 1991. During that year, the prison population grew by 3,903 fewer prisoners than had been projected because the number of new admissions to prison did not grow as expected. This 3,900 prisoner shortfall resulted in a reduction of estimated prison population for the year 1996 that was ten times as great. In the autumn of 1991, it was anticipated that 132,972 prisoners would be in the system in $1996 ; 40,000$ fewer than had been projected 12 months previously. Figure 7 shows the contrast.

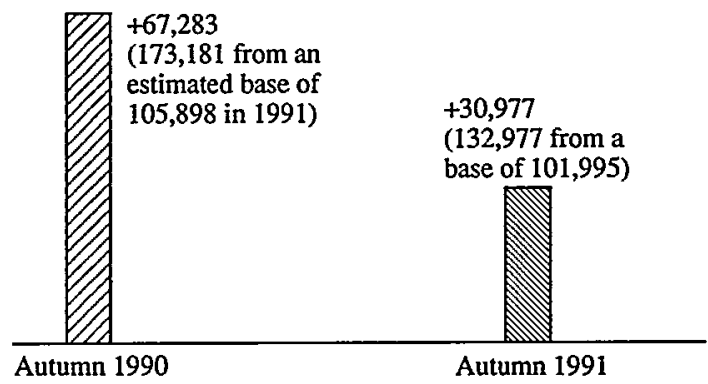

FIG. 7 Projected Change in Prison Population for California 1991-6: Two Estimates (California State Department of Corrections, 1990 and 1991) 
Analysis of the California projections suggests two reasons why long-range predictions are particularly prone to error during periods when correctional populations are undergoing either sharp expansion or contraction. First, so-called 'straight-line' projections assume that short-term trends will continue for longer periods. When periods of extraordinary change precede the projection, this is rather like seeing a coin flip turn up heads three times in succession and predicting heads for the next 27 trials.

A second problem generated by the California projections was that they inadvertently assume that penalties for felonies would grow harsher during the 1990s. The Department of Corrections projections tended to assume that the level of sentence severity in California would stay constant over the 1990s. Thus, it was assumed that the prison terms meted out over the 1990 s would be as long but no longer than the terms being imposed currently (California State Department of Corrections 1990). But the projection also assumed that the number of prison admissions would continue to increase at the rate that had been recently experienced in California. This assumed continued increase in the severity of punishment because one of the major reasons why prison admissions had been increasing in the late 1980 s was that the proportion of convicted offenders receiving prison sentences had increased.

We can illustrate the problem and show the inconsistency involved in the California projection methodology with a hypothetical example. Assume that the proportion of all convicted burglars sent to prison increased from 20 per cent to 40 per cent between Year 1 and Year 2 and that the average term of imprisonment each burglar received moved up from 12 months to 18 months. In that case, the California method would assume that the average prison sentence for burglary remained at 18 months when estimating Year 3 results because it assumes constancy in the level of punishment. But because it continues the trend in levels of prison admissions, the California method would estimate that the number of prison admissions in Year 3 would double again and grow to a level equal to 80 per cent of convicted burglars. We are aware of no basis on which this inconsistency can be resolved.

Of the two assumptions, consistency of level of severity and continuity in trend of severity, the assumption of consistency of level of severity seems much the more prudent. Thus, when changes in the proportion of offenders committed to prison are a significant part of the changes experienced in the level of prison admissions, this must be brought to the attention of those who undertake to make projections. We are not aware of a prior illustration of these problems that was as sudden in its impact or as large in its statistical effect as the California experience.

\section{Policy Perspectives}

An increase in prison population of the magnitude and suddenness of that in California is worthy of international attention whenever and wherever it occurs. But there are three dimensions beyond the scale of change in California that should be of special concern to those persons and offices involved in the analysis of correctional policy in democratic governments. The three policy lessons already available for international consumption concern: (a) the open-ended potential for prison population increase; (b) the error generated by straight-line correctional growth projections; and (c) the existence of volatile prison growth as a natural laboratory for assessing the impact of imprisonment on crime rates. 


\section{The open-ended potential for prison population increase}

Both the quality and quantity of change documented in California speak to the open-ended capacity for change in correctional systems. Most of the increased imprisonment in California was not directly related to either increases in crime or changes in population. Most crime levels in 1990 were close to their 1980 rates. While the state population had increased by 30 per cent, this element alone would have accounted for less than 10 per cent of the growth experienced by California prisons if rates of imprisonment per 100,000 had remained at 1980 levels. And the kinds of crime associated with the largest share in California's prison expansion-drug offences, housebreaking, and theft-are precisely the offences that flood the criminal justice systems of every major Western democracy. We think that the sorts of policy shifts observed in California could double the prison population of any country in Western Europe experiencing no net population growth or change in the volume or character of crime.

There is also a second respect in which prison growth in California was open-ended that is worthy of special attention. In the 1970s, Alfred Blumstein and his associates put forward a 'theory of the stability of punishment': a 'homeostatic hypothesis' according to which when a nation's prison population begins to fluctuate, pressure is generated to restore the prison population to a stable rate (Blumstein and Cohen 1973; Blumstein $e t$ al. 1976; Blumstein and Moitra 1979). This process of restoration

would typically be through some form of 'adaptation' by the various agencies within the nation's criminal justice system. One form of adaptation could result in changes in the manner in which discretion is exercised by the various functionaries within the criminal justice system. If prison populations get too large, police can choose not to arrest, prosecutors can choose not to press charges, judges can choose not to imprison, or parole boards can choose not to deny requests. (Blumstein and Moitra 1979: 376)

Under the 'homeostatic hypothesis' one would expect an increase in population or arrests that might exert upward pressure on prison population to be counteracted by forces that would push in the opposite direction. But what is remarkable in California is that every significant policy change during the 1980s pushed in the same direction. Compensatory or equilibrating forces were invisible in California prior to 1991. The absence of any apparent compensatory forces to bring about the 'homeostatic shifting' (Blumstein and Moitra 1979: 376) hypothesized by Blumstein and his associates was notable even as both total prison population and rate of imprisonment extended many standard deviations from previous average levels. It is further remarkable that not only did prison population movement run counter to the predictions of the theory of the stability of punishment, but that sentencing changes that continued through the middle and late 1980s also ran in precisely the opposite direction to that which the homeostatic hypothesis would predict.

There is one final way in which the prison growth in California was open-ended. There was no change in the formal penal law in the state of California that appears responsible for the changes in penal policy that occurred after 1980. The growth of imprisonment in California was thus a textbook illustration of the legal realist maxim that there is only a loose association between the law on the statute books and the law in action. The number of persons in confinement can double and triple with no change 
in the legal framework for criminal justice. The absence of any major statutory change to explain the California prison growth also means that changes in penal law will not necessarily serve as early warning signals of change in penal policy.

\section{The paradox of prison population projections}

Our earlier discussion of prison population projection exercises in California touched on errors in these exercises that were designed to estimate prison population in the late 1990 s and the year 2000. But the particular errors noted in those exercises should not divert attention from the more general problem-such exercises cannot provide useful long-range planning estimates when correctional populations have been fluctuating significantly.

We do not here suggest that all long-range correctional forecasts are inaccurate. No one has rigorously evaluated a set of such projections. We suspect that long-range projections made during periods of stability in correctional populations will project stable trends far into the future; not infrequently these will be correct. Figure $8 a$ shows a straight-line projection of future prison population (dotted line) derived from a stable recent history (straight line). Figure $8 b$, by contrast, displays recent growth in prison population (straight line) and two alternative future projections (dotted lines).
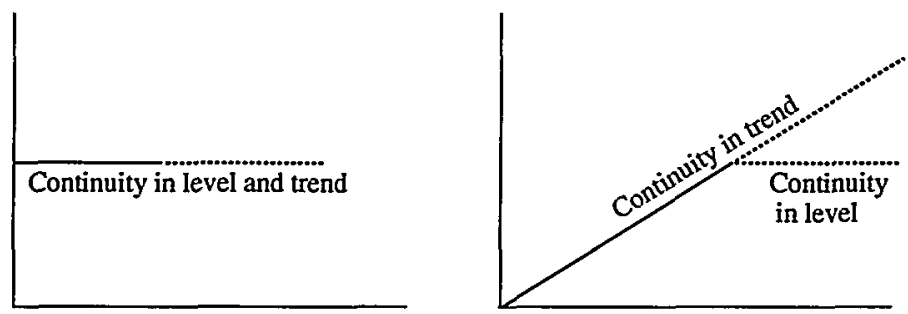

FIG. 8. Projections from Contrasting Hypothetical Recent Trends in Prison Population: (a) From Rate Stability. (b) From Recent Growth

The dotted line representing the higher projection in Figure $8 b$ reflects the assumption of continuity in trend from the historical data. The lower estimate reflected in the other dotted line was derived from the same historical data but assumes that prison population will remain stable at the level last noted in those data. Both are 'straight-line' projections; neither has a superior position a priori. One reason why the projection illustrated in Figure $8 a$ might lead to fewer errors is that there is no disagreement in such circumstances between estimates based on continuity in trend and estimates based on continuity in level: they are represented in the same dotted line.

The problem we wish to emphasize here is that long-range correctional projections are most unreliable when they are most needed-in the midst of changing circumstances. Indeed, there is no single projection with a superior claim to validity under such circumstances. Forecasts are least error-prone in those circumstances when they are less needed, during periods of exceptional stability. Their real function in such circumstances is to predict the obvious. Of course, even when populations have been stable, straight-line projections will frequently prove inaccurate. But when prison 
populations are already fluctuating significantly, the problem is intractable: either continuity-of-trend or continuity-of-level projections must be wrong and there is no way of choosing the most likely error.

The California data we have been discussing illustrate this point all too well. Throughout the $1980 \mathrm{~s}$, growth in the California prison population would best have been described by a continuity of trend projection, a trend which turned out to extend for a decade; much longer than historical patterns in California would have suggested. At the end of 1990, however, the rate of increase in prison admissions flattened to a pattern more closely approximating continuity in level from mid-1990. As Figure 7 demonstrates, this difference in short-term trend generated a discrepancy of 40,000 prisoners in two 1996 projections made one year apart. It is all but inevitable that this type of flattening out will eventuate. But when such changes will happen is beyond the competence of projection technology. And this renders prison population forecasting all but useless in volatile periods.

\section{The California experiment}

A final respect in which the California experience merits international attention is as a natural experiment on the impact of large changes in rates of imprisonment on rates of crime. A major intended effect of imprisonment is the reduction of the number of crimes committed in the community as the result of the incapacitation of persons who would re-offend if at liberty. This incapacitation potential is the clearest comparative advantage of imprisonment over non-incarcerative penal sanctions such as probation, fines, and community service orders. In the discussion of imprisonment policy, much is assumed and estimated about the volume of crime prevented as a result of particular levels of incarceration. Few of the estimates that have been put forward have been rigorously tested (see Shinnar and Shinnar 1975; Blumstein et al. 1978; Zedlewski 1987; Cohen and Canela-Cacho 1992).

The experience of California since 1980 provides an important opportunity for studying the effect of changes in imprisonment on crime rates. The California increases in imprisonment occurred over a relatively short time period without any contemporaneous major social dislocation or changes in the nature of government or criminal justice. The statistics on crime, population, and punishment in California are not without defects, but they are among the highest quality data which are available on these topics. While the 'natural experiment' we have in mind is not the equivalent of controlled experimentation, the opportunity presented in California to assess the impact of additional imprisonment on crime rates is the best we have yet observed.

\section{Conclusion}

The explosive growth in Galifornia's prisons was a revolution of practice rather than theory. The celebrated shift to 'just deserts' sentencing was not the mechanical cause of the huge increase in prison population that began four years later. These population shifts were not associated with long prison terms, and principally involved larger numbers of property and drug offenders being sentenced to prison (see Zimring and Hawkins 1992a: chapters 1, 3). While the shifting public mood that resulted in the reform in California sentencing may have also contributed to the discretionary 
decisions of prosecutors and judges to imprison that fed the prison population increase, this indirect connection is hardly the model of legislative influence that is usually put forward.

The California experience has shown that long-term projections of future correctional needs cannot be made during periods of volatile change in rates of imprisonment over the short term. Yet the state's Department of Finance was ready to ground a multi-billion-dollar building programme on nine-year prison population projections of 224,000 .

The radical change in penal policy that California has experienced may also be an unprecedented opportunity to assess the impact of so much extra imprisonment on crime rates. To have performed such a radical experiment without assessing its consequences would be unforgivable.

\section{REFERENCES}

Blumstern, A., and Conen, J. (1973), 'A Theory of the Stability of Punishment', Fournal of Criminal Law and Criminology, 64: 198-207.

Blumstern, A., Cohen, J., and Nagrn, D. (1976), 'The Dynamics of a Homeostatic Punishment Process', Journal of Criminal Law and Criminology, 67: 317-34.

—, eds. (1978), Deterrence and Incapacitation: Estimating the Effects of Criminal Sanctions on Crime Rales. Washington, DG: National Academy of Sciences.

Blumstein, A., and Mortra, S. (1979), 'An Analysis of Time Series of the Imprisonment Rate in the States of the United States: A Further Test of the Stability of Punishment Hypothesis', Journal of Criminal Law and Criminology, 70: 376-90.

California State Department of Gorrections (1990), Prison Population Projections, 1990-1996. Sacramento, GA: California State Department of Corrections.

- (1991), Prison Population Projections, 1990-1997. Sacramento, CA: California State Department of Corrections.

California State Department of Finance (1991), 1991 Capital Outlay and Infrastructure Report. Sacramento, CA: State Department of Finance.

Cohen, J., and Canela-Cacho J. (1992), 'Patterns in Incarceration for Violent Crime'. Paper prepared for the National Academy of Science's Panel on the Understanding and Control of Violent Behavior.

Shinnar, R., and Shinnar, S. (1975), 'The Effects of the Criminal Justice System on the Control of Crime. A Quantitative Approach', Law and Society Review, 9: 581-611.

US Department of Justice, Bureau of Justice Statistics (1992), Prisons and Prisoners in the United States. Washington, DG: US Department of Justice.

ZEDLEwskr, E. (1987), 'Making Confinement Decisions', National Institute of Justice Research in Brief. Washington, DC: National Institute of Justice.

Zimring, F. E. (1990), 'Correctional Growth in Context', in Growth and Its Influence in Correctional Policy. Proceedings of a conference, 10-11 May 1990, Berkeley, CA. Berkeley, CA: University of California, Center for Study of Law and Society.

Zimring, F. E., and FRASE, R. (1980), The Criminal Justice System: Materials on the Administration and Reform of the Criminal Law. Boston: Little, Brown and Company.

Zimring, F. E., and Hawkins, G. (1991), The Scale of Imprisonment. Chicago: University of Chicago Press. 
FRANKLIN E. ZIMRING AND GORDON HAWKINS

(1992a), The Search for Rational Drug Control. Cambridge, MA: Cambridge University Press.

(1992b), Prison Population and Criminal Justice Policy in California. Berkeley, CA: University of California, Institute of Governmental Studies. 